\title{
EDITORIAL
}

\section{Advancement of psychiatric research in Ireland: proposal for a national body}

The personal, social and economic burdens of psychiatric illness in Ireland are not being matched by clinical and preclinical biomedical and psychosocial research of an appropriate breadth and depth. At least two factors appear involved - the amount of research interest and commitment on the one hand, the extent of financial resources available for such research on the other. Of these two factors, greater emphasis tends to be placed on financial shortcomings. It is certainly true that the monies available for psychiatric research are modest and the influence of such a shortage on the quantity and quality of research should not be underestimated. The plight of the Health Research Board illustrates the problem with regard to central funding. The relatively low priority afforded to psychiatric research funding by government is sadly matched by the low priority afforded it by the general public - mental illness occupying a relatively lowly place behind cancer, heart disease and physical disability when it comes to sums raised through voluntary appeal.

However, we must also recognise that it is unwise to blame the lack of funds alone. Research is often not given the priority it requires. It is a matter of congratulations that in recent years considerable attention has been paid, for example, to the improvement of post-graduate psychiatric training, the accrediation of hospitals, the monitoring of educational standards. There has been much discussion too concerning the need to improve the quality of clinical services. Perhaps it is inevitable that in the midst of these developments and discussions the issue of psychiatric research has tended to occupy a back seat. Perhaps it would even be said that a pattern has developed whereby research has been given a lower place in the hierarchy of professional endeavour and activity in psychiatry than has perhaps been the case in other branches of medicine.

In other parts of the world, specific bodies have been created which have, as their central remit, the fostering of psychiatric research, the training of research workers, the raising of research funds and the political lobbying, centrally and locally, on behalf of research to assist the plight of the mentally ill by increasing knowledge relating to the causes and treatment of psychiatric ill-health. The question arises: should such a body be established in Ireland and what should its role be? Issues such as the appropriate name of such a body (one suggestion is the Institute of Psychiatry in Ireland), its location and precise administrative organisation, would appear to take second place to the question of whether such a body or organisation be established at all. We recognise, however, that such issues are potentially highly sensitive. At this stage, however, it would seem better to confine discussion to setting up such a body which would include amongst its aims, the following:

1. The cultivation, facilitation and development in Ireland of clinical and preclinical biomedical psychosocial research into psychiatric disorders.
2 . The training of young psychiatrists and graduates in related biomedical and psychosocial fields in research skills and the provision of research opportunities for such graduates during and after their higher postgraduate training.

3. The provision of a focus for research collaboration for the dissemination of research information relating to psychiatric disorders.

4. The raising of funds on a national and international basis for clinical and preclinical biomedical and psychosocial research relating to psychiatric disorders and for training in research methods.

The cause of psychiatric research needs a powerful voice arguing its importance within psychiatry and medicine and in discussion with the Department of Health, the Royal College Division of Psychiatry, the Irish Psychiatric Training Committee and similar bodies, organisations and groups. Psychiatric research currently falls between too many stools. It needs a coherent, informed and consistent voice of its own.

At this stage it makes sense to leave the agenda relating to any such proposed organisation or body as open as possible. Obviously, however, the selection of a name acceptable to the great majority of involved people would be a considerable help in terms of conveying the ethos and purpose of such an endeavour. The views of anyone crucially involved in Irish psychiatry on the contents of this editorial are urgently sought.

We would be very grateful therefore if respondents would:-

(a) indicate in general their attitude to the proposal that a body be set up with a specific remit and responsibility for psychiatric research in Ireland, North and South;

(b) suggest in the event of approving of such a development what might be an appropriate name;

(c) indicate their view as to the structure and function of such an institute;

(d) express any other views on the subject, including comments on this editorial;

(e) indicate whether respondents will be able to attend a meeting arranged for Friday, November 9th in Dublin to assess the proposal and responses. In the light of the responses we receive we propose to amend our proposal. Should a substantial number of people indicate support for the central issue, namely the setting up of such a body, we would hope to proceed by putting the amended proposal to all those interested in Irish psychiatric research.

Prof. Anthony Clare, Trinity College Dublin, Department of Psychiatry. Prof. Robert J. Daly, University College Cork, Department of Psychiatry. Dr. Timothy G. Dinan, Trinity College Dublin, Department of Psychiatry. Dr. David King, The Queen's University of Belfast, Department of Therapeutics and Pharmacology. Prof. Brian E. Leonard, University College Galway, Department of Pharmacology. Prof. Ciaran O'Boyle, Royal College of Surgeons in Ireland, Department of Psychology. Prof. Joyce O'Connor, Social Research Centre, University of Limerick. ${ }^{*}$ Dr. John Waddington, Department of Clinical Pharmacology, Royal College of Surgeons in Ireland, 123 St. Stephen's Green, Dublin 2. Prof. Noel Walsh, University College Dublin, Department of Psychiatry. Prof. Marcus Webb, Trinity College Dublin, Department of Psychiatry.

* Correspondence. 